\title{
ПРОБЛЕМЫ В СТАТИСТИКЕ ВНУТРИРОССИЙСКОЙ МИГРАЦИИ, ПОРОЖДЕННЫЕ ИЗМЕНЕНИЕМ МЕТОДИКИ УЧЕТА В 2011 г.
}

\section{НИКИТА МКРТЧЯН}

\begin{abstract}
Статистика долговременной внутренней миграции в 2011 2. претерпела серьезные изменения, связанные с включением в число мигрантов лии, зарегистрированных не только по месту жительства, но и по месту пребывания на срок 9 месяцев и более. Эти изменения привели к резкому увеличению числа учтенных мигрантов, изменению структурных характеристик потоков. В результате изменения методики учета, сразу после окончания срока регистрации мигрант автоматически считается выбывшим в обратном направлении. В статье проанализированы последствия появления в статистике внутристрановой миграции новой категории - «возвратившиеся после временного отсутствия», выявлены связанные с этим проблемы оценки масштабов миграции, ее направлений, влияния миграции на численность населения отдельных территорий страны. Кроме того, показано, что текущая методика статистического учета искажает структурные характеристики миграции, наиболее сильно в молодых возрастах.
\end{abstract}

Ключевые слова: внутренняя миграция, возраст мигрантов, статистика миграции, Россия, причины миграции, учебная миграция.

Качество статистики миграции в России никогда не было идеальным, оно почти всегда подвергалось критике со стороны экспертного сообщества или пользователей. Несовершенен учет долговременных и временных (возвратных), внутристрановых и международных перемещений. Пожалуй, наиболее активно проблема обсуждалась в 2000-е годы, когда, с одной стороны, был накоплен определенный опыт анализа миграции в России после осмысления регулярно публикуемых данных ${ }^{1}$, с другой стороны, стало ясно, что информация о миграционных процессах не вполне адекватна сложившейся ситуации (Чудиновских 2001), а в целом состояние системы оценивалось как критическое (Чудиновских 2004).

Система учета долговременной миграции в России в постсоветский период претерпела ряд коренных трансформаций, часть которых касалась всей миграции (например, замена системы прописки, на которой базировался текущий учет миграции в России, на систему регистрации по месту жительства и месту пребывания), часть - только международной миграции. Учет временной миграции иностранных граждан фактически создавался с нуля, учет внутристрановых возвратных перемещений практически прекратился. Изменения системы текущего учета носили неоднозначный характер, часть из них вели к его ухудшению (Мкртчян 2003), часть позволяла учитывать миграцию более полно (Чудиновских 2010).

\footnotetext{
НИКИТА ВЛАДИМИРОВИч МКРТЧЯН (nmkrtchyan@hse.ru), НАЦИОНАЛЬНЫЙ ИССЛЕДОВАТЕЛЬСКИЙ УНИВЕРСИТЕТ «ВЫСШАЯ ШКОЛА ЭКОНОМИКИ», РОССИЙСКАЯ АКАДЕМИЯ НАРОДНОГО ХОЗЯЙСТВА И ГОСУДАРСТВЕННОЙ СЛУЖБЫ ПРИ ПРЕЗИДЕНТЕ РОССИЙСКОЙ ФЕДЕРАЦИИ (РАНХИГС), РОССИЯ.
}

ИССЛЕДОВАНИЕ ВЫПОЛНЕНО В РАМКАХ НАУЧНО-ИССЛЕДОВАТЕЛЬСКОЙ РАБОТЫ ГОСУДАРСТВЕННОГО ЗАДАНИЯ РАНХИГС.

СТАТЬЯ ПОСТУПИЛА В РЕДАКЦИЮ В ДЕКАБРЕ 2019 Г.

\footnotetext{
${ }^{1}$ В России данные текущего учета миграции начали регулярно публиковаться с начала 1990-х годов.
} 
Несмотря на то, что внимание было в большей мере приковано к проблемам учета международной миграции, учет переселений в пределах страны также не выглядел адекватным. Масштабы учитываемых долговременных перемещений неуклонно снижались в течение 1990-х годов, а в 2000-е замерли на уровне около 2 млн человек. О недоучете внутристрановых миграционных перемещений свидетельствовали как данные переписей 2002 и 2010 г. (Мкртчян 2009), так и ряд объективно узких мест статистики долговременной миграции, фактически исключающих из нее лиц, долгое время проживающих вне места постоянного проживания (регистрации по месту жительства), даже при условии того, что они регистрировались по месту пребывания на длительный срок. В какой-то мере проблему позволяли сглаживать данные переписей населения, однако их качество также вызывает критику (Андреев 2012).

После Всероссийской переписи 2010 г. система статистического учета долговременной миграции в России претерпела коренные изменения, они коснулись как международной, так и внутренней миграции. С 2011 г. как долговременных мигрантов стали учитывать зарегистрированных не только по месту жительства, но и по месту пребывания на срок 9 месяцев и более. Эти изменения преследовали две цели: обеспечение более полного охвата процедурами учета разных категорий долговременных мигрантов и приведение российской системы учета миграции в соответствие с Рекомендациями ООН 1998 г. по статистике миграции (Чудиновских 2019).

В результате изменений методики учета 2011 г. резко увеличилось количество учтенных долговременных международных и внутренних мигрантов, число последних удвоилось в течение 2011-2012 гг. Новые правила учета позволили получить представление о ранее латентных или полулатентных категориях мигрантов, например, о перемещающихся в связи с получением высшего образования (Кашницкий 2017), оценка их миграций теперь представляется более адекватной, чем ранее.

Но в то же время новая система учета породила новую проблему. Сразу по окончании регистрации по месту пребывания на любой срок мигрант считается выбывшим к месту постоянной регистрации. Эксперты уже высказывают правомерные сомнения в том, что не все мигранты, регистрирующиеся на срок 9 месяцев, соответствуют международно признанному критерию делимитации долговременной миграции (1 год), указывают на возможный недоучет мигрантов, многократно регистрирующихся на короткий срок, недоучет выезда до окончания срока регистрации (Чудиновских 2019) и др.

Для статистики внутренней миграции, на наш взгляд, наиболее важным является вопрос о переучете числа долговременных мигрантов. Есть обоснованные сомнения в том, что «выбытия» по окончании срока регистрации в реальности происходят. На самом деле, по окончании срока регистрации возможны следующие варианты развития событий:

1. мигрант (будем так называть человека, ранее оформившего регистрацию по месту пребывания) в действительности возвращается к месту постоянного проживания, в данном случае процедура учета в части фиксации его выезда работает адекватно;

2. мигрант оформляет новую регистрацию по месту пребывания в том же поселении (на любой срок), не выбывая к месту постоянной регистрации. В данном случае 
статистика фиксирует повторное выбытие и прибытие, но численность населения места нового и прежнего проживания не меняется;

3. мигрант оформляет новую регистрацию по месту пребывания в другом поселении или регионе (на любой срок), реально совершая переселение в данном направлении, но опять же, не выбывая к месту постоянной регистрации. В данном случае статистика фиксирует фиктивное повторное выбытие к месту прежнего проживания, но численность населения места нового и прежнего проживания может меняться только вследствие разнесенности во времени этих событий;

4. мигрант не оформляет новой регистрации по месту пребывания, но остается проживать в месте временного пребывания. В таком случае статистика фиксирует фиктивное выбытие, что сказывается на численности населения двух территорий, его структурных характеристиках.

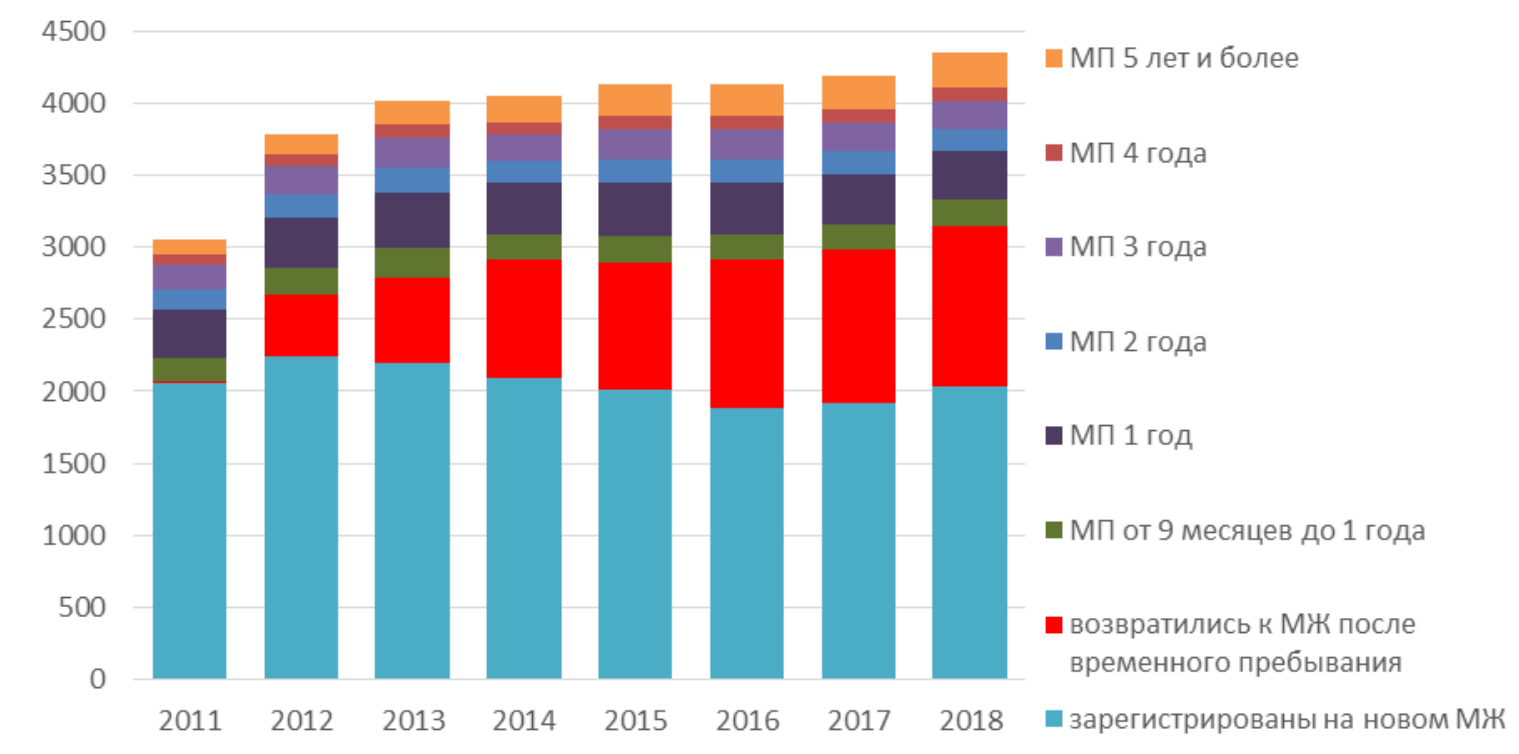

Рисунок 1. Зарегистрированные по видам и срокам регистрации, внутренняя миграция, 2011-2018 гг., тыс. человек

Примечание: МП -место пребьвания, МЖ-место жительства.

Источник: Росстат, текущиий учет.

Понятно, что и после 2011 г. внутрироссийские мигранты могли переезжать на любой срок и не оформлять регистрацию по месту жительства или пребывания, что в определенной мере (но не понятно, в какой) компенсирует переучет вследствие фиктивных прибытий/выбытий. Но проблемы статистики долговременной миграции связаны не только с реалистичностью масштабов внутристрановой миграции, но и с адекватностью оценки населения регионов, муниципальных образований и отдельных поселений, структурных характеристик миграции и др., связанных с появлением новой категории в статистике миграции - «возвратившиеся/выбывшие к месту жительства после временного пребывания на другой территории». В 2011 г. число «возвратившихся» составляло всего 10,8 тыс. человек, но в следующие годы оно стало быстро расти и после 2016 г. превысило 1 млн или примерно 25\% всех внутристрановых переселений (рисунок 1). Поэтому изменение 
методики учета мигрантов имело как скорый эффект, в полной мере проявившийся уже в 2011 г., так и отложенные последствия, масштабы которых стали понятны через несколько лет и осмысливаются только сейчас.

Цель данной статьи - обозначить проблемы, связанные с появлением этой новой статистической категории мигрантов, предостеречь исследователей от ошибок и неверных трактовок и интерпретаций данных при анализе процессов внутренней долговременной миграции.

В статье использованы данные текущего учета внутренней миграции, в основной своей части находящееся в открытом доступе, т. е. опубликованные в официальных статистических изданиях, базах данных Росстата. Неопубликованные данные относятся к детальному выделению возрастных групп мигрантов, на которых новые проблемы могут быть видны, как нам представляется, наиболее выпукло.

\section{РАЗНЫЙ ВРЕМЕННОЙ ЛАГ ВЛИЯНИЯ ИЗМЕНЕНИЯ МЕТОДИКИ УЧЕТА НА ЧИСЛО ПРИБЫТИЙ И ВЫБЫТИЙ}

Данная проблема прежде всего проявилась в международной миграции, так как уже в 2011 г. резко увеличился миграционный прирост населения России. Число прибывших резко выросло, а число выбывших в течение этого года осталось на прежнем уровне, так как даже зарегистрированные на срок 9 месяцев могли попасть в число снятых с учета лишь к концу года. Выбытия стали расти с 2012 г., в реальности система пришла в некое подобие состояния равновесия примерно к 2015-2016 гг. Однако резкий рост чисел прибывших, например, вследствие событий на Украине в 2014-2015 гг., также приводил прежде всего к увеличению числа прибытий и миграционного прироста населения России, а через 2-3 года, если число прибытий не росло или сокращалось - к «отложенному» росту числа выбытий и сокращению миграционного прироста. По той же причине, после быстрого роста чисел прибывших в Россию долговременных мигрантов из Узбекистана и Таджикистана в 20112013 гг., в 2015 г., после сокращения числа прибытий, Россия получила убыль в миграционном обмене с Узбекистаном и близкий к нулю миграционный прирост в обмене с Таджикистаном, чего до этого ни разу не наблюдалось.

Сходные проблемы в статистике внутрироссийской миграции не привлекали такого внимания, но они также имели место. Например, сразу после изменения методики учета резко возросли масштабы перераспределения населения между городскими поселениями и сельской местностью (рисунок 2). Но уже в 2014 г. масштабы перетока населения начали сокращаться, а с 2016 г. он вернулся на уровень, отмечавшийся до 2011 г., и стабилизировался. Подобным образом в 2011-2012 гг. усилилось перераспределение населения между отдельными частями страны. Во внутренней миграции резко усилилась поляризация: центры притяжения стали интенсивнее расти, места оттока - испытывать более интенсивный отток населения. Однако баланс миграции по регионам страны зависит в том числе и от местных факторов, так что проследить влияние на него изменений методики учета не так просто. 


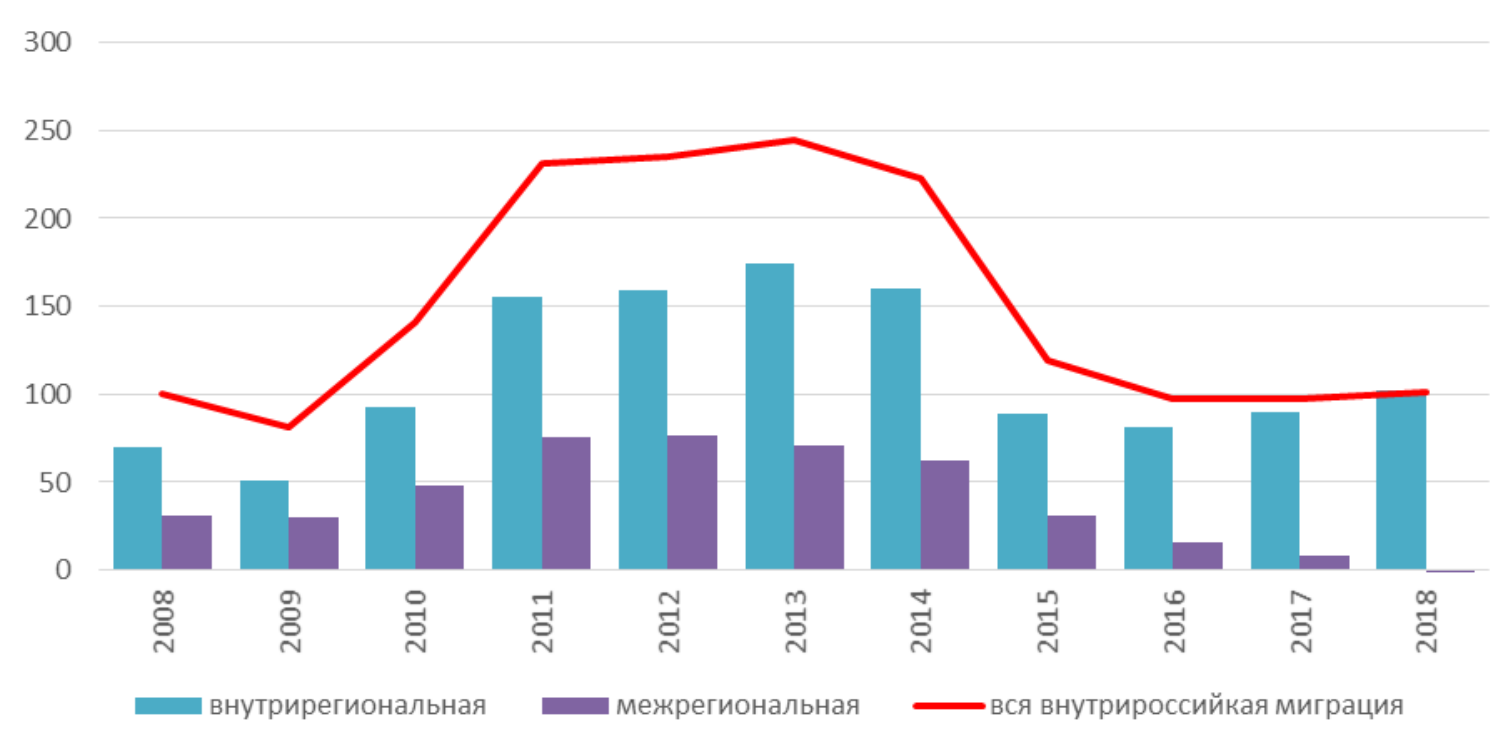

Рисунок 2. Миграционный прирост городского населения России в результате внутрироссийской миграции, тыс. человек

Источник: Росстат, текущий учет.

Стоит повторить, что остается проблемой недоучет долговременной миграции. В частности, отток населения, прежде всего молодежи, из сельской местности в реальности выше, чем отражает статистика. Результаты исследований отдельных сельских поселений в глубинке отдельных регионов России показывают, что порядка 30\% официально числящегося в них населения на самом деле в селах не проживают, особенно велико расхождение в возрастах 20-40 лет (Фомкина 2017; Алексеев, Воробьев 2018).

\section{ПРОБЛЕМЫ, СВЯЗАННЫЕ С ИСКАЖЕНИЕМ ВОЗРАСТНОЙ СТРУКТУРЫ МИГРАЦИИ И ЧИСЛЕННОСТИ НАСЕЛЕНИЯ ОТДЕЛЬНЫХ ВОЗРАСТОВ НА РЕГИОНАЛЬНОМ И ЛОКАЛЬНОМ УРОВНЯХ}

С изменением методики учета в 2011 г. очень быстро претерпел изменение возрастной профиль миграции, в нем четко обозначился пик, связанный с учебной миграцией (Кашницкий 2017). По сравнению с 2010 г., к 2018 г. число фиксируемых статистикой переселений увеличилось в 2,2 раза, но в возрасте 18-21 лет рост этого показателя превысил 3,5 раза. Однако если в 2011-2013 гг. четко проявился пик только в возрасте 18 лет, то в последующие годы стал появляться второй пик в возрасте 21 год, которого в первые годы не было (рисунок 3). Доступной статистики распределения «возвратившихся» мигрантов по возрасту у нас нет, но, по всей вероятности, этот пик связан именно с возвратившимися после временного пребывания на другой территории. Также проявились иные пики миграции, приуроченные к возрастам 2-3 и 6 лет, что связано с необходимостью регистрации при записи детей в детские дошкольные учреждения (ДДУ) и школы. Немало семей с детьми, проживая без регистрации в местах, отличных от места их постоянной регистрации, оформляют ее именно по достижении их детьми этого возраста. 


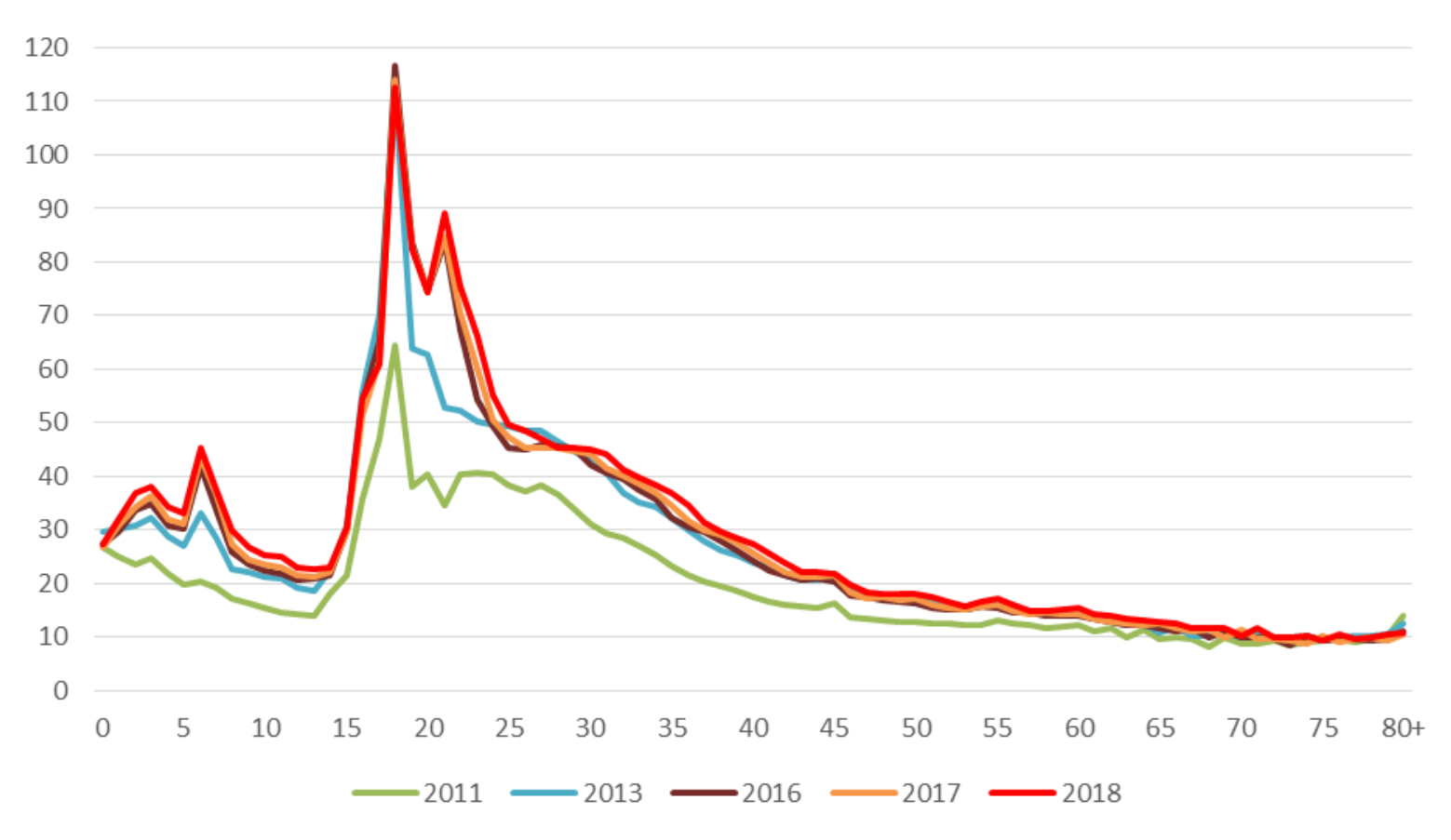

Рисунок 3. Возрастные коэффициенты внутри- и межрегиональной миграции, Россия, на 1000 населения соответствующего возраста

Источник: Росстат, текущуий учет.

Таблица 1. Прирост населения за счет межрегиональной миграции, 2018 г., на 1000 населения соответствующего возраста, топ-10 регионов-лидеров и аутсайдеров по значению показателя

\begin{tabular}{c|l|c|l|l}
\hline $\begin{array}{c}\text { Место в рейтинге } \\
\text { по значению } \\
\text { показателя }\end{array}$ & & $15-19$ лет & \\
\hline 1 & & & & $20-24$ года \\
2 & г. Санкт-Петербург & 67,6 & Чукотский АО & 62,7 \\
3 & Томская область & 37,1 & Ленинградская область & 56,0 \\
4 & г. Москва & 29,4 & Республика Тыва & 53,7 \\
5 & г. Севастополь & 25,0 & Мурманская область & 33,7 \\
6 & Ленинградская область & 20,1 & Сахалинская область & 25,3 \\
7 & Ярославская область & 17,2 & Московская область & 23,9 \\
8 & Новосибирская область & 16,9 & Камчатский край & 23,5 \\
9 & Воронежская область & 15,7 & Ямало-Ненецкий АО & 21,1 \\
10 & Ростовская область & 9,1 & Ханты-Мансийский АО & 20,5 \\
& Московская область & 8,1 & Республика Алтай & 17,6 \\
76 & & & & $-9,2$ \\
77 & Республика Хакасия & $-25,0$ & Смоленская область & $-11,0$ \\
78 & Республика Алтай & $-26,5$ & Хабаровский край & $-11,5$ \\
79 & Камчатский край & $-26,9$ & Новосибирская область & $-11,6$ \\
80 & Ямало-Ненецкий АО & $-27,7$ & Республика Мордовия & $-13,8$ \\
81 & Республика Калмыкия & $-30,9$ & Воронежская область & $-14,0$ \\
83 & Магаданская область & $-32,2$ & Курганская область & $-15,4$ \\
84 & Республика Коми & $-32,3$ & Омская область & $-17,2$ \\
\hline
\end{tabular}

Источник: Росстат, текущчий учет. 
Почему пик миграции, приходящийся на возраст 21 год, интерпретируется как следствие «возвращений»? Мы рассчитали интенсивность прироста населения в межрегиональной миграции в возрастных группах 15-19 лет и 20-24 года по отдельным регионам страны, она наглядно демонстрирует, что именно те регионы, которые наиболее активно теряли молодежь в возрасте 15-19 лет, лидировали по притоку 20-24-летних (таблица 1). Особенно наглядно перемещение в «рейтинге» таких регионов, как СанктПетербург, Томская область, являющихся крупнейшими центрами притока молодежи в этих возрастах, и наиболее отточных - Республики Тыва и Чукотского АО (От Волги до... 2019). Отметим, что противонаправленность потоков миграции в этих возрастах демонстрируют и данные Всероссийской переписи населения 2010 г. (Mkrtchyan, Vakulenko 2019), однако эти потоки не настолько равноценны. Расчеты на основе передвижки возрастов показывают, что отток молодежи после окончания школы из сельских районов Центральной России восполняется возвращением в очень малой степени (Kashnitsky 2020), невысокий процент намерений вернуться после обучения показывают и данные социологических обследований (Florinskaya 2017).

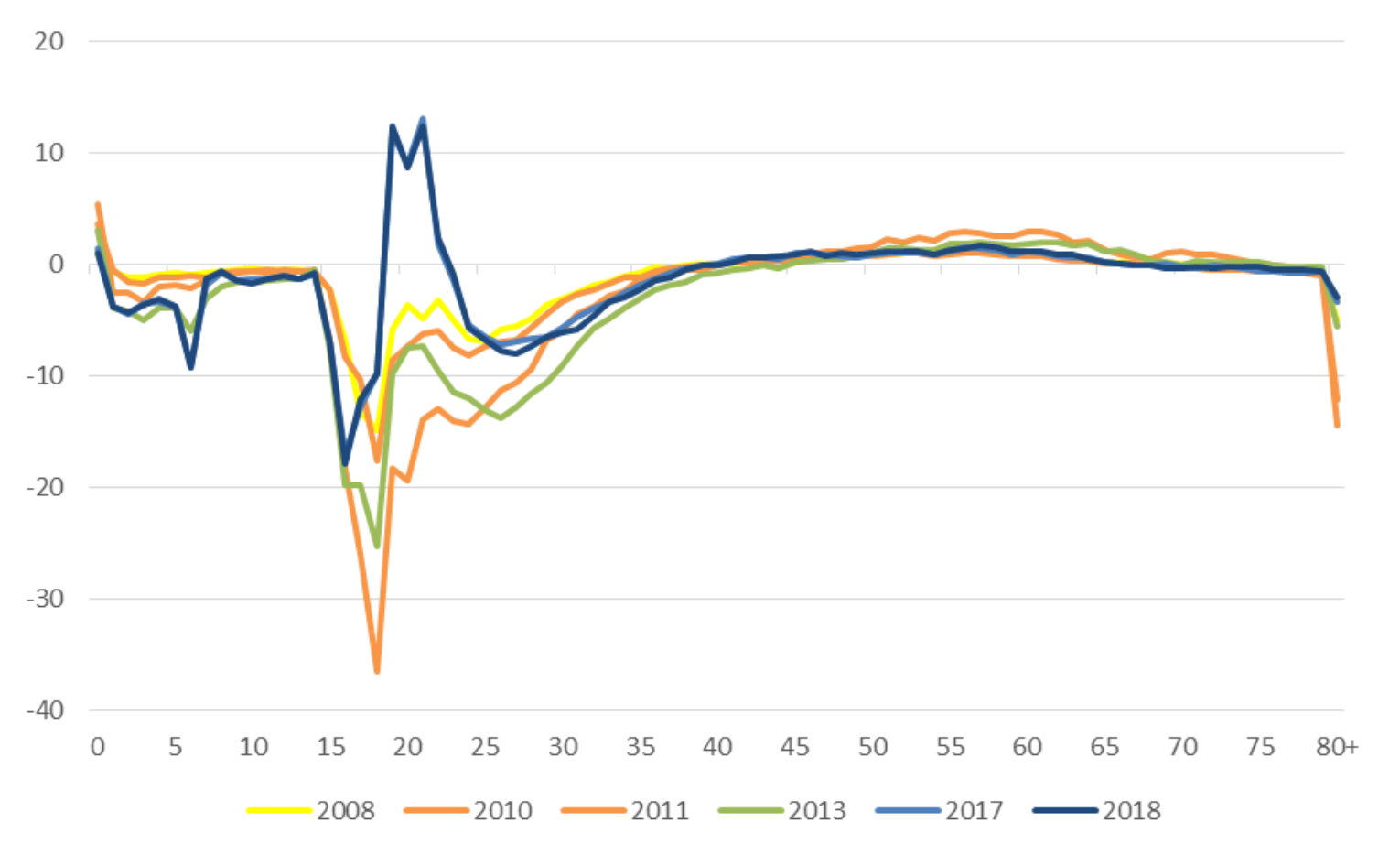

\section{Рисунок 4. Миграционный прирост (убыль) сельского населения России по возрастным группам, тыс. человек}

Источник: Росстат, текущий учет.

Подобным образом после изменения методики учета миграции в 2011 г. менялась возрастная структура перераспределения населения между городскими и сельскими поселениями. Вплоть до 2010 г. пик миграционной убыли сельского населения во внутрироссийской миграции приходился на возраст 17-18 лет, в целом значительные миграционные потери сельская местность несла до возраста 30 лет, в 40-60-летнем возрасте отток сменялся слабым притоком, с 70-летнего возраста отток вновь возобновлялся (это укладывается в общемировые тенденции - люди «старших» пожилых возрастов 
нередко, овдовев и оставшись без поддержки, покидают сельскую местность и переселяются в города (Serow 1996), подобное отмечают и российские исследователи (Карачурина, Иванова 2017)). Изменение методики учета в 2011 г. поначалу привело к резкой поляризации возрастного профиля баланса миграции, но не изменило его (рисунок 4). Однако уже к 2014 г. пик миграционного оттока сместился на возраст 16 лет и в последующем закрепился за этим возрастом. В возрастах же 19-22 года сельское население начало получать миграционный прирост населения, чего до этого не наблюдалось.

В 2011 г. резко выросли выбытия из сельской местности в самых молодых возрастах, начиная с 16 лет, причем прежде всего в результате внутрирегиональной миграции. В этом возрасте дети массово заканчивают основную школу (9 классов) и поступают в учреждения среднего профессионального образования (СПО), где заканчивают обучение к возрасту 18-20 лет. Учреждения СПО чаще всего базируются в городских поселениях, немало выпускников сельских школ переезжают в них в целях обучения, чаще всего - в ближайший подходящий город своего региона. По окончании обучения они считаются «возвратившимися», что, в силу, по-видимому, массовости предшествующего оттока, перекрывает выезд молодежи в города в целях получения высшего образования (пик оттока с этой целью, кроме того, приходится на возраст 18 лет). Насколько реален этот возврат, непонятно, возможно, выпускники системы СПО массово и не остаются в городах сразу после получения образования. Хотя немалая часть из окончивших СПО впоследствии поступает в вузы.

В целом есть обоснованные сомнения, что фиксируемые статистикой «возвращения» молодежи после учебы имеют такие масштабы, какими их видит текущий учет. Реальный масштаб возвращений после учебы, к сожалению, скрыт в фактах формального окончания регистрации после временного проживания молодых людей в местах получения образования. При этом происходит завышение численности населения регионов и поселений, получивших существенный приток населения в результате «возвращения». Что не менее важно, искажается число лиц в молодых, фертильных возрастах и, вероятно, существенно, - возрастные коэффициенты рождаемости. Возможно, пусть и не в такой степени, искажение численности населения и в иных возрастах.

В целях более адекватного представления о масштабах перетока населения указанных молодых возрастов между регионами, между городскими поселениями и сельской местностью лучше рассматривать группу населения 15-24 года суммарно. Это вынужденная мера. Более глубокому изучению процесса способствует большая дезагрегация данных, но в данном случае она, к сожалению, скорее приведет к искажению результатов анализа. 


\section{ИСКАЖЕНИЕ ИНЫХ СТРУКТУРНЫХ ХАРАКТЕРИСТИК МИГРАЦИОННЫХ ПОТОКОВ}

Статистика долговременной миграции, помимо данных о масштабах и направлениях переселений и базовых демографических характеристиках мигрантов (пол, возраст), содержит немало иной информации, например, об уровне образования мигранта, его семейном положении, занятости, причинах миграции и др. Эта информация записывается при регистрации по месту жительства или пребывания. В течение времени, на которое человек оформляет регистрацию, его социально-демографические характеристики могут изменяться. Но если часть характеристик изменяется предсказуемо (возраст увеличивается к окончанию срока регистрации, и его можно легко пересчитать), то изменение других характеристик невозможно отследить, не привлекая к этому самого человека или, например, административные данные, где такая информация может содержаться.

Росстат собирает и публикует информацию о причинах миграции лиц в возрасте 14 лет и старше. Очень большая часть переселений связана с достаточно неопределенными причинами: «причины личного, семейного характера», не дифференцированные на более точные причины, «иные причины» и «причина не указана». Остальные причины можно связать с работой, учебой, переселениями в составе семьи и др. В 2011-2015 гг. на эти причины приходилось от 45 до 48\% переселений, остальные оставались неопределенными.

Однако с 2016 г. Росстат, помимо вышеупомянутых (работа, учеба и т.п.), стал указывать в качестве причины миграции «возвращение после временного отсутствия», и эта причина сразу же оттянула на себя 26,5\% всех внутристрановых миграционных перемещений. В международной миграции в 2016-2018 гг. на эту категорию пришлось 95\% выбывших (Чудиновских 2019). При этом, как говорилось выше, возвращение после временного отсутствия стало возможным уже в 2011 г., а указывать ее в качестве отдельной причины стали только в 2016 г., когда число таких «возвращающихся» превысило четверть всех фиксируемых статистикой внутристрановых миграционных переселений. Получается, что «возвращающиеся» в 2011-2015 гг. скрывались за другими причинами, судя по всему, причина, указанная при регистрации, автоматически фиксировалась и по ее окончании. Но это явно приводило к искажению информации о реальных причинах миграции.

Так, в молодых возрастах в структуре причин миграции очень важную роль играют перемещения с целью учебы. Вплоть до 2015 г. роль этой причины возрастала, в группе 18-19-летних достигла 76\% (рисунок 5). Некоторыми экспертами это интерпретировалось как результат роста образовательной миграции после введения ЕГЭ. Но после того, как в 2016 г. «возвращение после временного отсутствия» было включено в число причин миграции, эта причина оттянула на себя 36-37\% всех причин миграции в возрасте 18-19 лет и 40-43\% в группе 20-24 года. В возрасте 18-19 лет она немногим уступала причине «в связи с учебой», а в возрасте 20-24 года стала главной. Доля остальных причин миграции соответственно сократилась, в наибольшей мере - миграция в связи с учебой. Видимо, в 20-24-летнем возрасте эту причину указывают те, кто переезжает в связи с продолжением обучения в магистратуре, аспирантуре и на иных формах поствузовского образования. 
18-19 лет

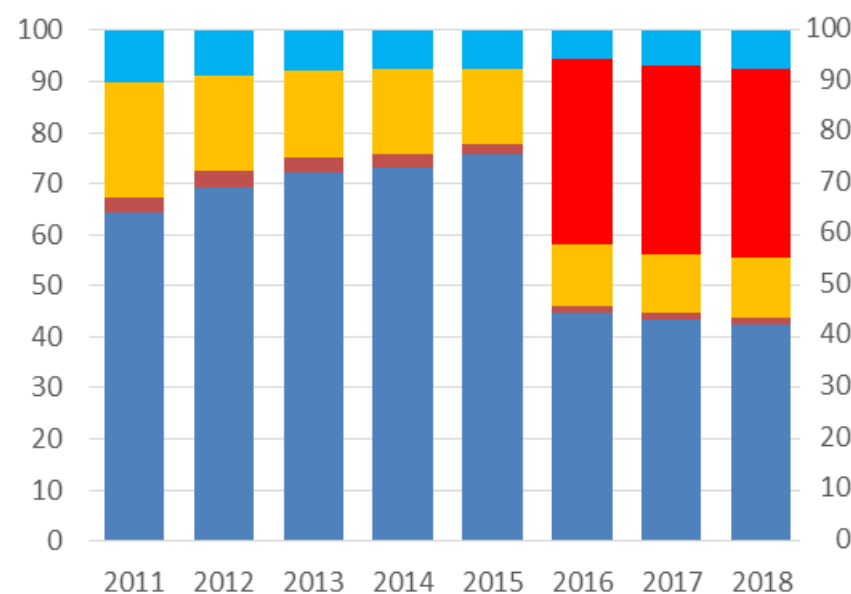

иные причинь

причины личного, семейного характера

в связи с учебой
20-24 года
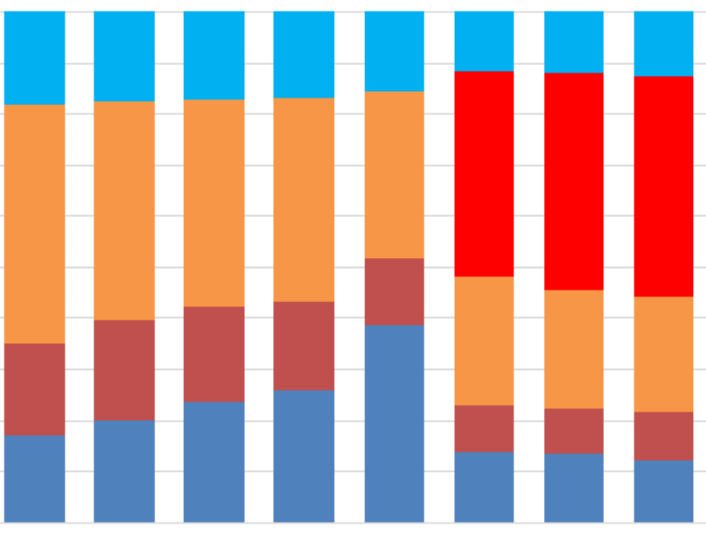

$20112012 \quad 2013 \quad 2014 \quad 2015 \quad 2016 \quad 2017 \quad 2018$

в возвращение после временного отсутствия

в в связи с работой

\section{Рисунок 5. Внутрироссийские мигранты в возрасте 18-19 лет и 20-24 года по причинам миграции, 2011-2018, \%}

Источник: Росстат, текущий учет.

Интересно, что, если смотреть на общее распределение внутрироссийских мигрантов по уровню образования, подобных скачкообразных изменений не происходило, доля переселенцев с высшим образованием плавно росла, увеличившись на 1,7 п.п. за 2011-2018 гг., что в целом, видимо, соответствует увеличению доли высокообразованного населения в стране в эти годы. Однако доля лиц с высшим образованием в общем числе мигрантов в возрасте 20-24 года неуклонно снижалась (таблица 2). В то же время, число лиц со средним образованием в возрасте 20-24 года увеличилось со 109,6 тыс. в 2011 г. до 197,4 тыс. в 2018 г., а их доля - с 23,5 до 38,2\%. По всей видимости, это связано с массовым «возвращением после временного отсутствия», особенно после 2015 г., тех, кто в 2011 и последующие годы переезжал с целью получения образования. Подавляющее большинство этой цели достигали, их уровень образования менялся, однако статистика миграции учитывала возвратившихся с тем уровнем образования, который они указывали при поступлении на учебу - чаще всего средним общим (полным). Т.е. уровень образования мигрантов в этом возрасте явным образом искажается, ежегодно сотни тысяч людей мигрируют с целью получения образования, но результат статистика миграции не отражает.

В иных возрастах доля лиц с высшим образованием среди мигрантов увеличивалась. Отметим, что в России после 25 лет уровень образования может меняться у сравнительно небольшой доли населения, процесс получения высшего образования к этому возрасту обычно завершается.

Кроме того, в течение 2011-2018 гг. в структуре внутрироссийских мигрантов увеличивалась доля лиц, не указавших образование, их число росло с 186,2 тыс. в 2011 г., 260,2 тыс. в 2012 г. до 507,0 тыс. в 2018 г. Однако число «возвратившихся после временного отсутствия» в 2018 г. составило 961 тыс. человек, и его резкий рост пришелся на период 
после 2012 г. Получается, что, если часть «возвратившихся» и попадала в категорию «не указавших уровень образования», она не была преобладающей.

Таблица 2. Доля лиц с высшим образованием в общем числе мигрантов соответствующего возраста, миграция в пределах России, \%

\begin{tabular}{crrrrrrrrrrr}
\hline & 2011 & 2012 & 2013 & 2014 & 2015 & 2016 & 2017 & 2018 \\
\hline \multicolumn{2}{c}{ Всего } & 26,8 & 26,9 & 26,6 & 27,5 & 27,1 & 28,0 & 28,2 & 28,5 \\
\multicolumn{2}{c}{ В том числе в возрасте, лет } & & & & & & & \\
$14-15$ & $\ldots$ & $\ldots$ & $\ldots$ & $\ldots$ & $\ldots$ & 0,0 & 0,0 & 0,2 \\
$16-17$ & 0,0 & $\ldots$ & $\ldots$ & $\ldots$ & $\ldots$ & 0,0 & 0,0 & 0,1 \\
$18-19$ & 0,7 & 0,6 & 0,6 & 0,6 & 0,5 & 0,5 & 0,4 & 0,5 \\
$20-24$ & 26,0 & 25,1 & 24,0 & 23,8 & 19,3 & 18,4 & 17,3 & 17,5 \\
$25-29$ & 41,9 & 41,7 & 41,4 & 42,8 & 42,4 & 43,2 & 43,1 & 42,7 \\
$30-39$ & 36,7 & 37,1 & 37,2 & 39,0 & 39,8 & 41,1 & 41,6 & 42,0 \\
$40-49$ & 30,9 & 31,4 & 30,8 & 31,7 & 32,3 & 33,6 & 34,1 & 34,5 \\
$50-54$ & 26,8 & 27,1 & 27,0 & 28,0 & 28,7 & 29,8 & 29,9 & 30,1 \\
$55-59$ & 24,3 & 24,2 & 24,0 & 25,1 & 25,6 & 26,8 & 27,0 & 27,6 \\
$60-64$ & 23,0 & 22,6 & 22,9 & 23,5 & 24,0 & 24,9 & 25,5 & 25,7 \\
$65-69$ & 20,7 & 22,8 & 22,9 & 23,4 & 23,3 & 24,1 & 24,2 & 24,6 \\
$70-74$ & 14,4 & 14,7 & 15,2 & 16,5 & 18,5 & 21,6 & 23,4 & 24,1 \\
$75-79$ & 9,5 & 10,5 & 11,8 & 12,3 & 13,4 & 15,4 & 15,5 & 16,6 \\
$80+$ & 5,1 & 5,5 & 6,0 & 6,5 & 7,2 & 8,3 & 9,5 & 11,0 \\
\hline
\end{tabular}

Источник: Росстат, текущฺий учет.

Видимо, уровень образования мигрантов в России, особенно в молодых возрастах, занижен, так как «возвращающиеся» после учебы остаются с уровнем образования 4-5летней давности.

Таблица 3. Доля лиц с высшим образованием в общем числе выбывших мигрантов соответствующего возраста, миграция в пределах России, \%

\begin{tabular}{l|rr|r|r|r|r}
\hline & \multicolumn{2}{|c|}{ Москва } & \multicolumn{2}{c|}{ Санкт-Петербург } & \multicolumn{2}{c}{ Томская область } \\
\cline { 2 - 7 } & 2011 & 2018 & 2011 & 2018 & 2011 & 2018 \\
\hline Всего & 43,2 & 21,8 & 41,5 & 41,9 & 29,7 & 28,1 \\
В том числе в возрасте, лет & & & & & \\
$18-19$ & 1,5 & 0,7 & 2,2 & 0,8 & 0,7 & 0,6 \\
$20-24$ & 34,0 & 6,5 & 33,3 & 20,8 & 27,7 & 12,4 \\
$25-29$ & 53,8 & 24,6 & 56,8 & 56,9 & 45,3 & 47,5 \\
$30-39$ & 53,2 & 29,0 & 52,8 & 58,8 & 42,4 & 45,3 \\
$40-49$ & 49,6 & 27,4 & 45,1 & 49,2 & 35,2 & 37,9 \\
$50-54$ & 45,4 & 26,5 & 39,6 & 42,7 & 30,1 & 38,0 \\
$55-59$ & 43,5 & 27,4 & 35,8 & 40,6 & 28,1 & 32,7 \\
$60-64$ & 39,8 & 28,5 & 33,1 & 37,7 & 23,7 & 28,8 \\
$65-69$ & 39,7 & 30,8 & 31,5 & 37,6 & 23,2 & 22,3 \\
$70-74$ & 33,2 & 31,6 & 27,3 & 37,4 & 13,0 & 25,1 \\
$75-79$ & 26,3 & 27,0 & 23,2 & 31,7 & 7,9 & 15,8 \\
$80+$ & 17,0 & 19,6 & 17,6 & 22,4 & 4,1 & 9,4 \\
\hline
\end{tabular}

Источник: Росстат, текущчий учет.

В России есть ряд регионов, являющихся явными центрами притяжения учебных мигрантов, к их числу, в первую очередь, относятся Москва, Санкт-Петербург и Томская область (От Волги до... 2019). Именно из этих регионов должны массово «возвращаться» в свои регионы мигранты, получившие высшее образование, и подавляющее их большинство будет в возрасте 20-24 года. Сравнение данных за 2011 и 2018 гг. показывает, что в общем числе выбывших доля лиц с высшим образованием в Санкт-Петербурге и Томской области 
мало изменилась, в Москве же существенно снизилась (таблица 3). Данные Росстата показывают, что в Москве в 2011 г. и в более поздние годы по непонятной причине многие мигранты не указывали уровень образования, хотя в числе выбывших еще в 2010-2011 гг. их доля была невелика. Видимо, по мере того, как эти не указавшие уровень образования лица переходили в категорию «возвращавшихся к месту жительства после временного пребывания» в столице, они начинали изменять и статистику выбытий в сторону увеличения доли не указавших уровень образования.

Если же обратить внимание на возрастную группу 20-24 года, то в ней доля лиц с высшим образованием резко снизилась в 2018 г., по сравнению с 2011 г., во всех трех регионах. Получается, что после получения образования люди из этих регионов не уезжают (выбывших с высшим образованием мало), а уезжают какие-то недоучки. Но на самом деле мы имеем дело все с той же проблемой - искажением текущим учетом реального уровня образования у очень большой доли мигрантов.

Подобным же образом обстоят дела с иными характеристиками порядка 1 млн внутрироссийских мигрантов - они в той или иной мере искажены.

\section{ЗАКЛЮЧЕНИЕ}

После изменения методики учета миграции, уже в 2011 г. статистика зафиксировала существенные изменения процесса перераспределения населения между поселениями разных типов, а также между регионами. Проявились резко выраженные возрастные пики миграции, до этого сглаженные или вовсе невидимые. Однако неизбежное появление при изменившейся системе учета миграции категории «возвратившихся после временного отсутствия», с временным лагом в 3-4 года снова привело к сглаживанию их влияния на население мест оттока и вселения. Но скорее всего реального сглаживания не происходит или оно происходит в значительно меньшей степени, из-за того что многие «возвращения» происходят только на бумаге.

А если это так, то это означает, что масштабы регистрируемой миграции в России завышены. По нашей оценке, реальные масштабы внутрироссийской долговременной миграции в последние годы составляют не 4,1-4,3 млн человек, как следует из данных Росстата, а находятся в вилке 3,1-4,3 млн человек. Нижние границы такой оценки, помимо предположения о том, что все или почти случаи «возвращения» являются фиктивными, обосновывают и результаты Всероссийской переписи населения 2010 г.: согласно ее данным, за год до переписи 3,1 млн человек сменили место постоянного проживания, похожие оценки масштабов внутренней миграции давались по результатам переписи населения 2002 г. (Мкртчян 2009). В то же время по-прежнему некоторая часть долговременных перемещений россиян остается вне статистического учета, так как перемещающиеся не оформляют регистрацию. Это, вместе с предположением о низкой доле фиктивных возвращений, дает основания предположить и более высокие оценки масштабов миграции, близкие к оценкам Росстата.

Статистическими данными о структуре миграционных потоков с 2011 г. следует пользоваться с большой осторожностью. Исследователи должны отдавать себе отчет в том, 
что характеристики мигрантов, которые могли претерпеть изменения за период «временного пребывания на другой территории» (уровень образования, семейное положение и др.) статистический учет может оценивать неадекватно, что мы и пытались показать в этой статье.

Для повышения качества анализа процессов внутренней миграции и оценки численности населения регионов, муниципальных образований и поселений было бы целесообразно, чтобы Росстат отдельно выделял в публикациях и статистических разработках категорию «возвратившиеся/выбывшие к месту жительства после временного пребывания на другой территории». Такое выделение позволит получать реальные структурные характеристики остальных мигрантов, даже если существующая методика учета не позволяет корректно учитывать их для «возвратившихся». Пока же для исследователей эта категория мигрантов является скорее помехой, чем подспорьем.

Многих проблем в интерпретации и анализе статистической информации о долговременной миграции удалось бы избежать, если бы Росстат своевременно и развернуто оповещал пользователей об изменениях в методике сбора и обработки статистической информации, а также о возникающих проблемах ее получения. Например, о проблемах статистики международной миграции в 2018 г. стало широко известно лишь в середине 2019 г. $^{2}$

Предстоящая Всероссийская перепись населения может, при качественном ее проведении, вскрыть отдельные неточности учета миграции. Например, она может показать реальное отсутствие молодежи после ее «возвращения» в сельскую местность или в малые городские поселения. С другой стороны, по результатам переписи, численность населения крупных городов может оказаться больше ее оценки на соответствующую дату, прежде всего за счет невыезда молодежи после обучения, а также иных категорий населения после окончания у них регистрации по месту пребывания. Возможно, перепись поможет в реальной оценке масштабов миграции в России за ряд предшествующих ей лет. Но все это возможно лишь при условии качественного проведения переписи, к двум предыдущим переписям населения имелось много вопросов (Андреев 2012; Мкртчян 2011).

\section{ЛИТЕРАТУРА}

Алексеев А.И., Воробьев М.И. (2018). Сколько сельских жителей в России зимой? Вестник Московского университета. Сер. 5. Геогр., 5, 104-107.

Андреев Е.М. (2012). О точности результатов российских переписей населения и степени доверия к разным источникам информации. Вопросы статистики, 11, 21-35.

Карачурина Л.Б., К.А. Иванова (2017). Миграция пожилых в России (по данным переписи населения 2010 г.). Региональные исследования, 3(57), 51-58.

Кашницкий И.С. (2017). Влияние изменений в правилах учета миграции в 2011 г. на оценку интенсивности миграции молодёжи: когортно-компонентный анализ.

\footnotetext{
2 Эксперты сообщили об аномальном притоке мигрантов в начале года // РБК, 23 июля 2019 г. Подробнее на РБК: https://www.rbc.ru/economics/23/07/2019/5d36c6ef9a7947f42d42668b
} 
Демографическое обозрение, 4(1), 83-97.

DOI: https://doi.org/10.17323/demreview.v4i1.6989

Мкртчян Н.В. (2003). Возможные причины снижения иммиграции в Россию в 20002001 гг. Вопросы статистики, 5, 47-51.

Мкртчян Н.В. (2009). Миграционная мобильность в России: оценки и проблемы анализа. Социальная Политика: Экспертиза. Рекомендации. Обзоры, 11, 149-164.

Мкртчян Н.В. (2011). Динамика населения регионов России и роль миграции: критическая оценка на основе переписей 2002 и 2010 гг. Известия РАН. Серия географическая, 5, $28-41$

Габдрахманов Н.К., Никифорова Н.Ю., Лешуков О.В. (2019). «От Волги до Енисея...»: образовательная миграция молодежи в России. Москва: Национальный исследовательский университет «Высшая школа экономики», Институт образования.

Фомкина А.А. (2017). Расхождения в оценках численности сельского населения (на примере Тверской области). Вестник Московского университета. Сер. 5. Геогр., 6, 88-91.

Чудиновских О.С. (2001). Состояние и перспективы текущего учета миграции в России. В: В.А. Ионцев (ред.) Статистика и учет миграции населения. Научная серия: Международная миграция населения: Россия и современный мир (Вып. 8, сс. 30-55). Москва: МАКС-Пресс.

Чудиновских О.С. (2004). О критическом состоянии учета миграции в России. Bonpocbl статистики, 10, 27-35.

Чудиновских О.С. (2010). Современное состояние статистики миграции в России: новые возможности и нерешенные проблемы. Вопросы статистики, 6, 8-16.

Чудиновских О.С. (2019). О пересмотре Рекомендаций ООН 1998 г. по статистике миграции в российском контексте. Bопросы статистики, 26(8), 61-76. DOI: https://doi.org/10.34023/2313-6383-2019-26-8-61-76

Florinskaya Y.F. (2017). School graduates from small towns in Russia: Educational and migration strategies. Studies on Russian Economic Development, 28(1), 87-96. DOI: https://doi.org/10.1134/S1075700717010038

Kashnitsky I. (2020). Russian periphery is dying in movement: a cohort assessment of internal youth migration in Central Russia. GeoJournal, 85(1), 173-185. DOI: https://doi.org/10.1007/s10708-018-9953-5

Mkrtchyan N., Vakulenko E. (2019). Interregional migration in Russia at different stages of the life cycle. GeoJournal, 84(6), 1549-1565. DOI: https://doi.org/10.1007/s10708-018-9937-5

Serow W.J. (1996) Demographic and socioeconomic aspects of elderly migration in the 1980s. Journal of Aging and Social Policy. 8(1), 19-37. DOI: https://doi.org/10.1300/J031v08n01_04 


\title{
PROBLEMS IN THE STATISTICS OF INTERNAL RUSSIAN MIGRATION CAUSED BY CHANGES IN ACCOUNTING METHODS IN 2011
}

\section{NIKITA MKRTCHYAN}

\begin{abstract}
The statistics of long-term internal migration in 2011 underwent serious changes related to the inclusion of persons registered not only at their place of residence, but also at their place of stay for a period of 9 months or more. As a result of these changes, a migrant whose registration has expired is immediately considered to have returned to his place of origin. This reform of statistical accounting has led to a sharp increase in the number of registered migrants and to a change in the structural characteristics of migration flows. The article analyzes the consequences of the appearance of a new category - "returning after a temporary absence" in the statistics of internal migration. The research also reveals the problems of assessing the extent of migration, its directions and the impact of migration on the population of certain territories of the country. In addition, it is proved that the existing methodology of statistical accounting distorts the structural characteristics of migration, especially at young ages.
\end{abstract}

Key words: Internal Migration, age of migrants, migration statistics, Russia, reasons for migration, educational migration.

Nikita MkRTchyan (nmkrtchyan@hse.ru), NATIONAL RESEARCh University Higher SchoOl of Economics, The Russian Presidential Academy of National Economy and Public Administration (RANEPA), Russia.

THE STUDY WAS CARRIED OUT AS PART OF THE RESEARCH WORK OF THE STATE ASSIGNMENT OF THE RANEPA

DATE RECEIVED: DECEMBER 2019.

\section{REFERENCES}

Alekseev A.I., Vorobyev M.I. (2018). Skol'ko sel'skih zhitelej v Rossii zimoj? [How many rural residents are there in Russia in winter?]. Vestnik Moskovskogo universiteta. Ser. 5. Geogr. [Moscow University Bulletin. Series 5. Geography], 5, 104-107. (In Russ.). Retrieved from https://vestnik5.geogr.msu.ru/jour/article/view/465/427

Andreev E.M. (2012). O tochnosti rezul'tatov rossiyskikh perepisey naseleniya i stepeni doveriya $\mathrm{k}$ raznym istochnikam informatsii [On the accuracy of Russian population census results and the level of confidence in different data sources]. Voprosy statistiki [Issues in statistics], 11, 21-35. (In Russ.)

Choudinovskikh O.S. (2001). Sostojanie i perspektivy tekushhego ucheta migracii v Rossii [Present State and Perspectives of Current Migration Registration in Russia]. In: V. Iontsev (Ed.), Statistika i uchet migracii naselenija. Nauchnaja serija: Mezhdunarodnaja migracija naselenija: Rossija i sovremennyj mir [Migration Statistics and Registration. Scientific Series: International Migration of Population: Russia and the Contemporary World] (8, pp. 30-55.). Moscow: MAX Press. (In Russ.)

Choudinovskikh O.S. (2004). O kriticheskom sostoyanii ucheta migratsii v Rossii [On the critical state of migration monitoring in Russia]. Voprosy statistiki [Issues in statistics], 10, 27-36. (In Russ.) 
Choudinovskikh O.S. (2010). Sovremennoe sostojanie statistiki migracii v Rossii: novye vozmozhnosti i nereshennye problemy [Modern state of statistics of migration in Russia: new possibilities and problems]. Voprosy statistiki [Issues in statistics], 6, 8-16. (In Russ.)

Choudinovskikh O.S. (2019). O peresmotre Rekomendacij OON 1998 g. po statistike migracii v rossijskom kontekste [On Revision of the UN Recommendations of Statistics of Migration (1998) an the Russian Context]. Voprosy statistiki [Issues in statistics], 8, 61-76. Retrieved from https://doi.org/10.34023/2313-6383-2019-26-8-61-76 (In Russ.)

Florinskaya Y.F. (2017). School graduates from small towns in Russia: Educational and migration strategies. Studies on Russian Economic Development, 28(1), 87-96.

DOI: https://doi.org/10.1134/S1075700717010038

Fomkina A.A. (2017). Rashozhdenija v ocenkah chislennosti sel'skogo naselenija (na primere Tverskoj oblasti) [Discrepancies in the rural population number estimates (case study of the Tver oblast)]. Vestnik Moskovskogo universiteta. Ser. 5. Geogr. [Moscow University Bulletin. Series 5. Geography], 6, 88-91. (In Russ.).

Retrieved from https://vestnik5.geogr.msu.ru/jour/article/view/371/354

Gabdrakhmanov N.K., Nikiforova N.Y., Leshukov O.V. (2019). "Ot Volgi do Eniseja...»: obrazovatel'naja migracija molodezhi v Rossii [«From Volga to Yenisei...» Educational Migration of Youth in Russia]. Moscow: Nacional'nyj issledovatel'skij universitet «Vysshaja shkola jekonomiki», Institut obrazovanija. [National Researxh University Higher School of Economics. Institute of Education]. (In Russ.). Retrieved from https://ioe.hse.ru/data/2019/09/13/1540804040/\%D1\%84\%D0\%B8\%D0\%BD\%D0\%B0\%D0 \%BB_\%D0\%A1\%D0\%90\%D0\%9E\%205(26)\%20\%D1\%8D\%D0\%BB\%D0\%B5\%D0\%BA $\% \mathrm{D} 1 \% 82 \% \mathrm{D} 1 \% 80 \% \mathrm{D} 0 \% \mathrm{BE} \% \mathrm{D} 0 \% \mathrm{BD} \% \mathrm{D} 0 \% \mathrm{BD} \% \mathrm{D} 1 \% 8 \mathrm{~B} \% \mathrm{D} 0 \% \mathrm{~B} 9 . \mathrm{pdf}$

Karachurina L.B., Ivanova K.A. (2017). Migracija pozhilyh v Rossii (po dannym perepisi naselenija 2010 g.) [Migration of the Elderly in Russia (According to 2010 Census Data)]. Regional'nye issledovanija [Regional study], 3, 51-58. (In Russ.). Retrieved from http://media.geogr.msu.ru/RI/RI_2017_03(57).pdf

Kasnitsky I. (2017). Vlijanie izmenenij v pravilah ucheta migracii v 2011 g. na ocenku intensivnosti migracii molodjozhi: kogortno-komponentnyj analiz [The Effect of the 2011 [Statistics Reform on the Estimations of Youth Migration Intensity: A Cohort-Component Analysis]. Demograficheskoe obozrenie, 4, 83-97.

DOI: https://doi.org/10.17323/demreview.v4i1.6989

Kashnitsky I. (2020). Russian periphery is dying in movement: a cohort assessment of internal youth migration in Central Russia. GeoJournal, 85(1), 173-185.

DOI: https://doi.org/10.1007/s10708-018-9953-5

Mkrtchyan N.V. (2003). Vozmozhnye prichiny snizhenija immigracii v Rossiju v 2000-2001 gg. [Possible reasons for immigration decrease to Russia in 2000-2001]. Voprosy statistiki [Issues in statistics], 5, 47-51. (In Russ.).

Mkrtchyan N.V. (2009). Migracionnaja mobil'nost' v Rossii: ocenki i problemy analiza [The migration mobility in Russia: assessment and methodological Problems]. Social'naja Politika: Jekspertiza. Rekomendacii. Obzory [Social Policy: Expertise. Recommendations. Overvievs], 11, 149-164. (In Russ.).

Mkrtchyan N.V. (2011). Dinamika nasjeljenija rjegionov Rossii i rol' migracii: kritičjeskaja ocjenka na osnovje pjerjepisjej 2002 i 2010 gg. [Population Dynamics of Russia's Regions and the Role of Migration: Critical Assessment Based on the 2002 and 2010 Censuses]. Izvestiya Rossiiskaya Akademii Nauk, Seriya Geograficheskaya, 5, 28-41. (In Russ.). 
Mkrtchyan N., Vakulenko E. (2019). Interregional migration in Russia at different stages of the life cycle. GeoJournal, 84(6), 1549-1565. DOI: https://doi.org/10.1007/s10708-018-9937-5

Serow W.J. (1996) Demographic and socioeconomic aspects of elderly migration in the 1980s. Journal of Aging and Social Policy, 8(1), 19-37.

DOI: https://doi.org/10.1300/J031v08n01_04 